\title{
Determination of Isoflavones in Nuts, Dried Fruits and Vegetables by High Performance Liquid Chromatography
}

\section{Teslima DAȘBAŞI ${ }^{1 *}$}

\begin{abstract}
In this study, the amounts of daidzin, daidzein and genistein of isoflavone components were determined in nuts, dried fruits and vegetables by high performance liquid chromatography (HPLC). Firstly, the extraction conditions like the rate of the aqueous and organic phase, the total volume of the extraction solution, time and rotation per minute of centrifugation were optimized. After extraction conditions were specified, the parameters of HPLC device have investigated. The isoflavone components were extracted by a mixture of $0.1 \%$ acetic acid and methanol $(20: 80 \mathrm{v} / \mathrm{v})$, at the room temperature. The chromatographic separation was conducted on C18 with wavelength of $260 \mathrm{~nm}$ at 30 ${ }^{\circ} \mathrm{C}$. The diode array detector was used. The analytical parameters given as the dedection and quantification limits, linearity, precision and accuracy were determined. The relative standard deviation of method was determinated $\leq 3 \%(\mathrm{n}=21)$ and the calibration curse was worked in the range 1-100 mg $\mathrm{L}^{-1}$. The total isoflavone concentration in real samples from Sivas centrum was determined in the range $9.6-469.1 \mu \mathrm{g} \mathrm{g}^{-1}$.
\end{abstract}

Keywords: Isoflavone, Daidzin, Daidzein, Genistein, HPLC

${ }^{1}$ Teslima DAŞBAŞI (Orcid ID: 0000-0002-8546-612X), Kayseri University, Bunyan Vocational School, Department Civil Defense and Firefighting, Kayseri, Turkey

*Sorumlu Yazar / Corresponding Author: Teslima DAŞBAŞI, e-mail: teslimadasbasi@hotmail.com 


\section{INTRODUCTION}

The phenolic groups, found naturally in plants, have suggested to have an effect like estrogen. The compounds of plant origin showing estrogenic properties are calledas phytoestrogens (Liggins et al., 2000; Bingham et al., 1998). Also, phytoestrogens are divided into following groups isoflavones, lignans, kumestans and stilbens (Küçükboyacı et al., 2013; Cos et al., 2003; Delmonte et al. 2006; Özhatay et al, 2009; Krenn et al., 2002). The phenolic compounds as a food component, affect flavor and odor formation, participates in the color formation and its change (King et al, 2008). While the properties of estrogenic and antiestrogenic of phytoestrogens are mostly used in the treatment of cardiovascular diseases, menopause symptoms and osteoporosis, on the other hand antioxidant properties of phytoestrogens are used in the treatment of cancers especially bowel, prostate and breast (Modaseri et al., 2011). In this sense, phytoestrogens are involved in the composition of many medicines due of their phytochemical content (Cos et al., 2003). Hazelnut, pistachio and almond in the oil seeds group are vegetable nutrients. These are high nutrients in terms of the pulp and energy content required for the operation of the digestive system (Durmaz and Gökmen, 2010). Oilseed plants contains Omega (n-3) fatty acids. That these fatty acids increase in diet, helps in the prevention of coronary heart disease, regulates blood sugar and lowers bad cholesterol while it also supports good cholesterol too. Nuts, peanuts and almonds are both excellent sources of protein, carbohydrates, vitamins and minerals and they contain phytochemical compounds such as isoflavone derivatives (Durmaz and Gökmen, 2010). Considering health, it is suggested that the consumption of vegetables and fruits is strongly related to some cancer types, cardiovascular diseases, diabetes and reduced of the functional loss risk concerning age (Stratil et al., 2006). It is emphasized that these effects are due to the antioxidant bioactive phytochemical components such as folate, potassium and beta - carotene, vitamin $\mathrm{C}$ and vitamin $\mathrm{E}$ in the fruits and vegetables (Prior and Cao, 1999; Prior et al., 2005). In recent studies, it has been found that phytoestrogens, spontaneously consumed through nutrition, have the effects identified as not only many beneficial effects but also some harmful side effects (Prior and Cao, 1999; Prior et al., 2005).

In many studies, it has been found that phytoestrogens have the estrogen-like biological activity and they compete with natural estrogens. The estrogenic effect of these compounds is poor and has been reported to affect fertility (Vila-Donat et al., 2015; Fukuda et al., 2011). For the reasons described above, the determination of the amount of isoflavone compounds in plant and food samples has gained importance in analytical studies. The first quantative data on isoflavonesin soy bean was presented out by Naim et. al. (Naim et al., 1974). This type of extraction process was performed with methanol, ethanol, acetonitrile, acetone or their mixtures with water (Tsao, 2010). The traditional method, the Soxhlet extraction, is one of the most commonly methods used to separate isoflavones from plant samples (Luque-Garcia and Luque de Castro, 2004). For extraction of isoflavones, methods such as ultrasonic-assisted extraction (UAE) (Abranko et al., 2015), supercritical fluid extraction (SFE) (Brglez Mojzer et al., 2016), microwave assisted extraction (MAE) (Rostagno et al., 2009), matrix solid-phase dispersion (MSPD) (Xiao et al., 2004), and accelerated solvent extraction (ASE) also known as pressurized liquid extraction (PLE) (Barros, et al., 2013) are more and more used thanks to the developing modern techniques.

In this study, the small amounts of samples were vortexed with a small amounts of the extraction solution mixture and lastly, centrifugated with the high speed in one step. Therefore, we realized a practical, fast, economical and simple extraction phase.

The isoflavone compounds have been identified in various plant and food samples by many analytical instruments such as liquid chromatography with optical / visible detector (Thomas et al., 2001; 
Franke et al., 2002; Maubach et al., 2003), liquid chromatography with electrochemical detector (Klejdus et al., 2004), gas chromatography-mass spectrometry (Grace et al., 2003), ultra performance liquid chromatography (Delgado-Zamarrenoet al., 2012), mass spectrometry-ultra-high performance liquid chromatography with solid phase extraction (Vila-Donatet al., 2015). In this sense, it has been seen that the previous studies more focused on soybean and soybean products for isoflavone determinations.

In this study, isoflavone derivatives were determined in some nuts and dried fruit / vegetable varieties so rarely founded in the literature. In this respect, the extraction method was applied on almonds, hazelnuts, peanuts, dried eggplant, zucchini, beans and peppers, dried apricot and grape varieties obtained from Sivas centrum. The amounts of daidzin, daidzein and genistein in almond, hazelnut, dried eggplant, zucchini, bean and pepper, dry apricot and grape varieties, widely consumed by Sivas's people and sold at the local markets in Sivas center, have been determined. The determination of isoflavone derivatives in the samples was made based on dry weights. Firstly, solid samples were extracted. For this study, the extraction state of affairs, the volume of the aqueous phase, the volume and type of the organic phase and the total volume of the extraction solution, were investigated. Subsequently, time and rotation per minute of centrifugation were studied for optimize of the extraction conditions. After optimizing the extraction conditions, the amounts of isoflavone compounds which are daidzin, daidzein and genistein were determined by a high performance liquid chromatograph on the $\mathrm{C} 18$ column at $30^{\circ} \mathrm{C}$. Standard solutions were prepared at known concentrations of analytes and the calibration lines were drawn. In the calculation of the quantities of the analytes, it has been benefited from the calibration line.

\section{MATERIALS AND METHODS}

\section{Instruments}

The samples used in study were vortexed by Phoenix Instrument RS-VA10, centrifuged by the NÜVE-NT-1200R instrument and homogenized with hand blender Arzum Ar1025 Smart Max. The parametres of HPLC device were optimized to the best peak of analytes. The measuring wavelength of the detector was selected to $260 \mathrm{~nm}$. The injection volume was $10 \mu \mathrm{L}$. In the separation and determination of daidzin, daidzein and genistein, the Agilent 1260 series HPLC instrument on C18 column (ACE, $25 \mathrm{~mm} 5$ micron) with wavelength of $260 \mathrm{~nm}$ at was used. The chromatographic conditions are given in Table 1.

Table 1. The chromatographic conditions

\begin{tabular}{ll}
\hline Instrument & Agilent 1260 series HPLC \\
HPLC column & $\mathrm{C} 18$ column, ACE (25 mm 5 micron) \\
Column Oven Temperature & $30{ }^{\circ} \mathrm{C}$ \\
Mobile Phase & $0.1 \%$ acetic acite (Mobile phase A); $100 \%$ methanol (Mobile phase B) \\
gradient separation & 0 min A:65, B:35 10 min A:0, B:100 \\
Dedector & DAD (Diode Array Dedector) \\
Wavelength & $260 \mathrm{~nm}$ \\
\hline
\end{tabular}

\section{Chemical Materials and Standards}

All chemicals used in the study taken from Merck, Darmstadt, Germany firm are analytical purity. The daidzin, daidzein and genistein standards were obtained from Sigma Aldrich, Steinheim, Germany with analytical purity suitable. 


\section{Sample Preparation and General Procedure}

The real samples, almond, hazelnut, pistachio, dried eggplant, pepper, pumpkin, bean, dried apricot, yellow and black grape, were taken from the local markets in Sivas.

After the samples were washed with distilled water and dried, powdered by hand blender to homogenize of these. 5 grams of the samples were weighed and taken to the centrifuge tube. Three parameters have been studied for each sample. $10 \mathrm{~mL}$ of a mixture of $0.1 \%$ acetic acid and methanol $(20: 80 \mathrm{v} / \mathrm{v})$, was added to the samples and then the samples vortexed for three minutes. Later, the samples were centrifuged at $10000 \mathrm{rpm}$ for 4 minutes. The extract solution was taken with autosampler and injected into a column of high performance liquid chromatography.

\section{Method Validation}

For validation of extraction method was examined linearity, detection limit (DL), quantification limit (QL), precision and accuracy. Standard solutions at known concentrations of analytes for the determination of daidzin, daidzein and genistein compounds were prepared in methanol medium. A calibration lines for daidzin, daidzein and genistein have drawn by measuring analyte concentrations, 1 , 5, 10, 20, 50 and $100 \mathrm{mg} \mathrm{L}^{-1}$, in standard solutions vesus the peak areas. The linear equations, correlation coefficient and slope are given in Table 2. DL and QL values were calculated on the basis of F x SD / b, where $\mathrm{F}$ is factor of 3 and 10 for DL and QL, respectively, SD is standard deviation of the blank solution $(n=21)$ and $b$ is slope of the linear equation. The DL for daidzin, daidzein and genistein are found as $0.28,0.28$ and $0.29 \mathrm{mg} \mathrm{L}^{-1}$, respectively. The QL of daidzin, daidzein and genistein were calculated as 0.92, 0.94 and $0.97 \mathrm{mg} \mathrm{L}^{-1}$, respectively. The gradient separation method was applied to real samples and standard solutions under optimal conditions at a wavelength of $260 \mathrm{~nm}$ at $0 \mathrm{~min}: 65 \% \mathrm{~B}: 35 \%, 10$ min: 0: $100 \%$ gradient.

Also, the mix standard solution, $100 \mathrm{mg} \mathrm{L}^{-1}$ of each separately daidzin, daidzein and genistein, was prepared according to high limit of quantification (HLOQ). The results are presented in Fig 1.

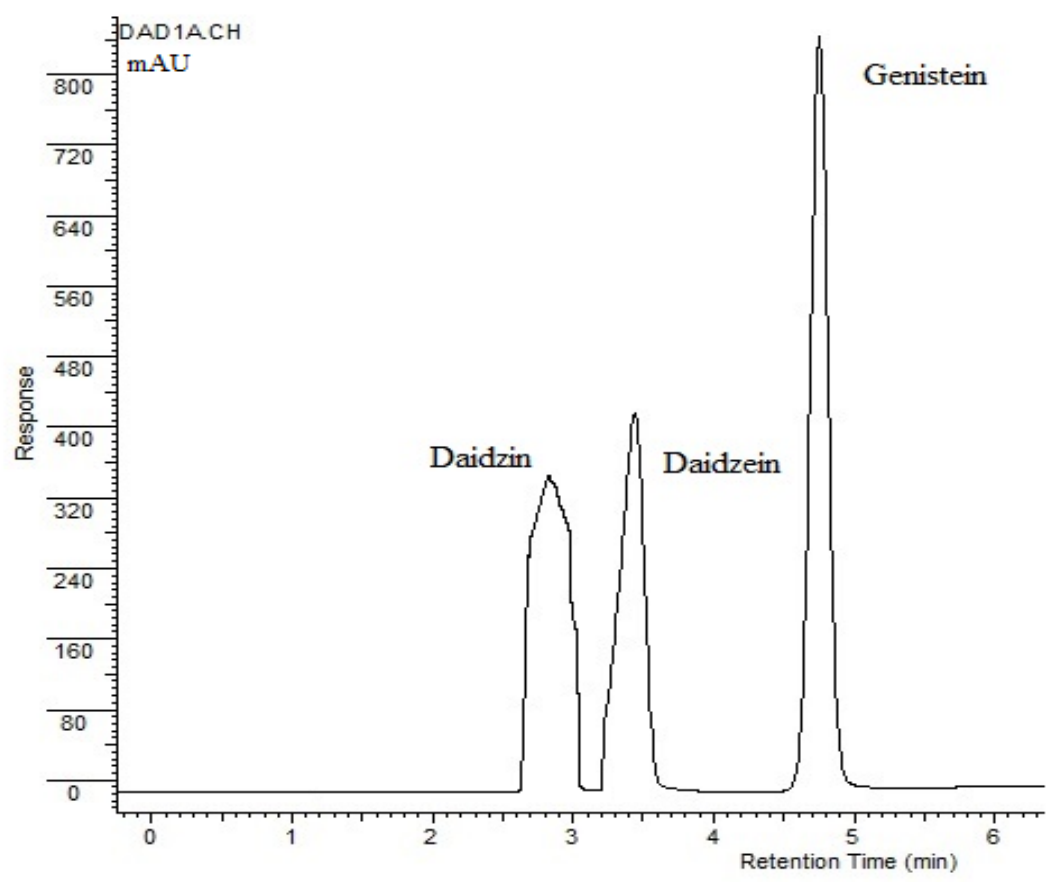

Figure 1. Chromotgram showing the retention peaks for $100 \mathrm{mg} \mathrm{L}^{-1}$ of each separately daidzin, daidzein and genistein. 
For optimization the extraction conditions, a series almond samples due to its high isoflavone content were prepared. To get the best peak, the developed method was applied to these almond samples.

Table 2. The characteristics of calibrated lines, where the concentration of working range for all three substances is $1-100 \mathrm{mg} \mathrm{L}^{-1}$ (signal DAD1A).

\begin{tabular}{lllc}
\hline Sample & RT $^{*}$ & Regression Equation & Correlation Coefficient \\
\hline Daidzin & 2.83 & $\mathrm{y}=4.4669 \mathrm{x}+39.525$ & 0.9993 \\
Daidzein & 3.41 & $\mathrm{y}=51.854 \mathrm{x}+57.526$ & 0.9995 \\
Genistein & 4.70 & $\mathrm{y}=78.633 \mathrm{x}-27.09$ & 0.9999 \\
\hline
\end{tabular}

*RT: Retention Time.

\section{EXPERIMENTAL}

\section{Determination and Optimization of Extraction Solvent}

That completely transfer of analytes to the extraction solution depends on the type and amount of organic solution. For the determination of the organic phase in the extraction mixture, the extraction solution mixtures were prepared by keeping constant the amount of $0.1 \%$ acetic acid $(2 \mathrm{~mL})$ and by using methanol, ethanol, ethylacetate and $\mathrm{n}$-hexane solutions $(8 \mathrm{~mL})$. To see which mixture given the best achieved result, 5 grams of almond samples were weighed. Extraction mixtures was injected into samples very quickly by a syringe, in this way extraction steps were applied to samples. Total isoflavone values were calculated according to the results obtained from the chromatogram. Total isoflavone values with respect to extraction solutions was shown in Figure 2. Methanol was chosen as the organic phase for subsequent experiments. After the organic phase was determined, the aqueous phase was determined. To do this, $2 \mathrm{~mL}$ of distilled water, acetic acid $(0.1 \%-1 \%)$ and nitric acid $(0.1 \%-1 \%)$ solutions, respectively were added and completed to $10 \mathrm{~mL}$ with methanol. After the almond samples were extracted with the obtained solution mixtures, the amounts daidzin, daidzein and genistein were determined by HPLC on C18.

As seen in Figure 3, the highest value was obtained with a $0.1 \%$ acetic acid-methanol mixture. After $0.1 \%$ acetic acid and methanol solutions were determined, $0,1,2,4,6,8$ and $10 \mathrm{~mL}$ of $0.1 \%$ acetic acid were added into centrifuge tubes and the final volume was completed to $10 \mathrm{~mL}$ with methanol. As shown in Figure 4, the best results were obtained with a mixture of $2 \mathrm{~mL}$ of $0.1 \%$ acetic acid and 8 $\mathrm{mL}$ of methanol.
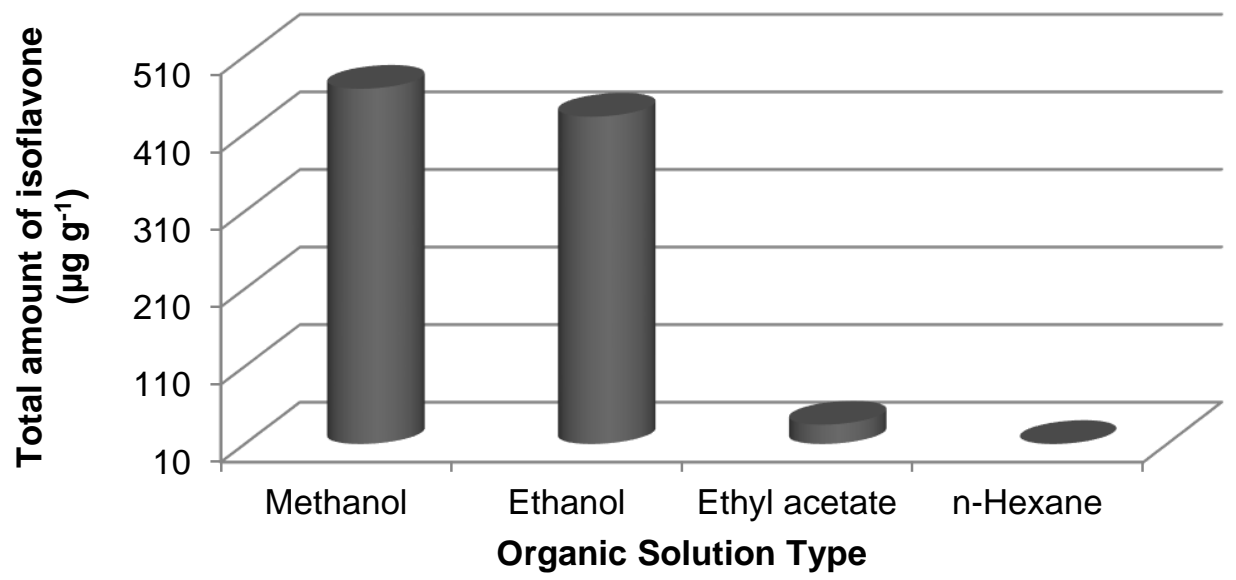

Figure 2. Determination of organic solution type. 


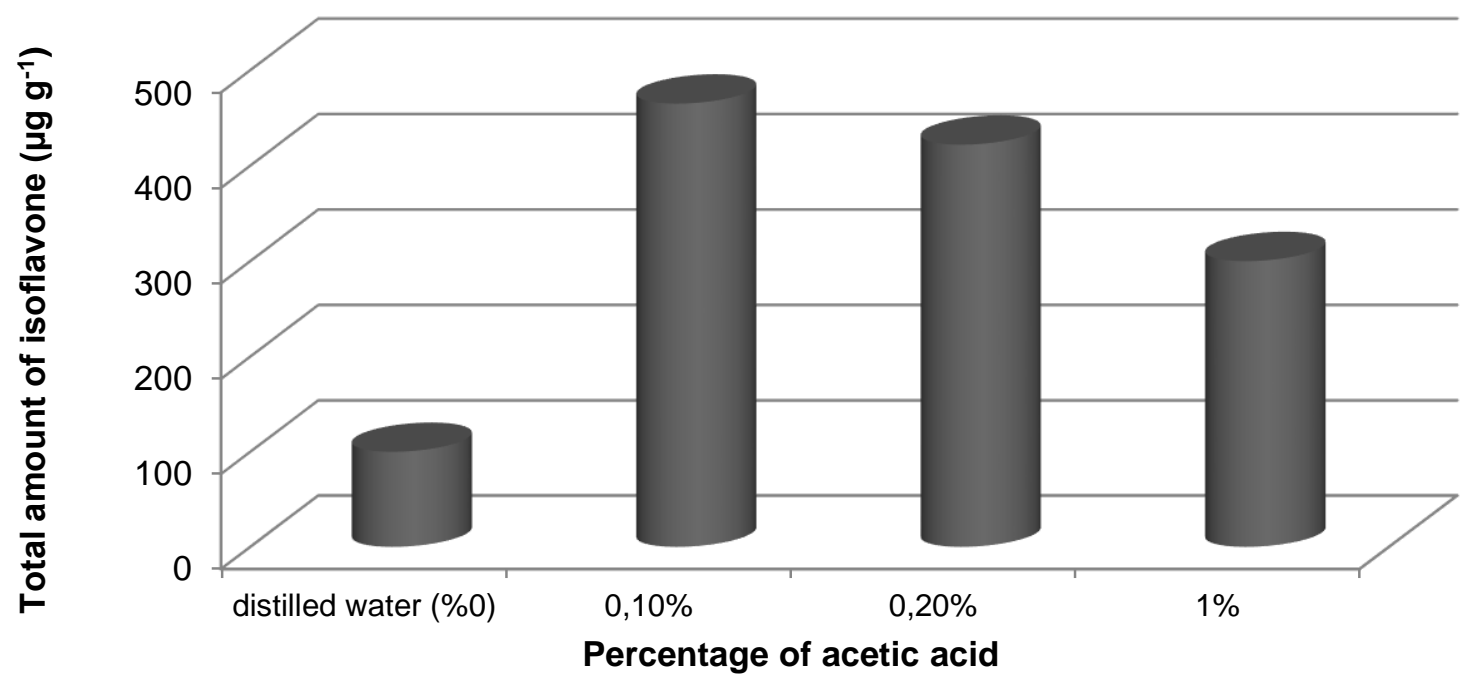

Figure 3. Percentage of acetic acid.

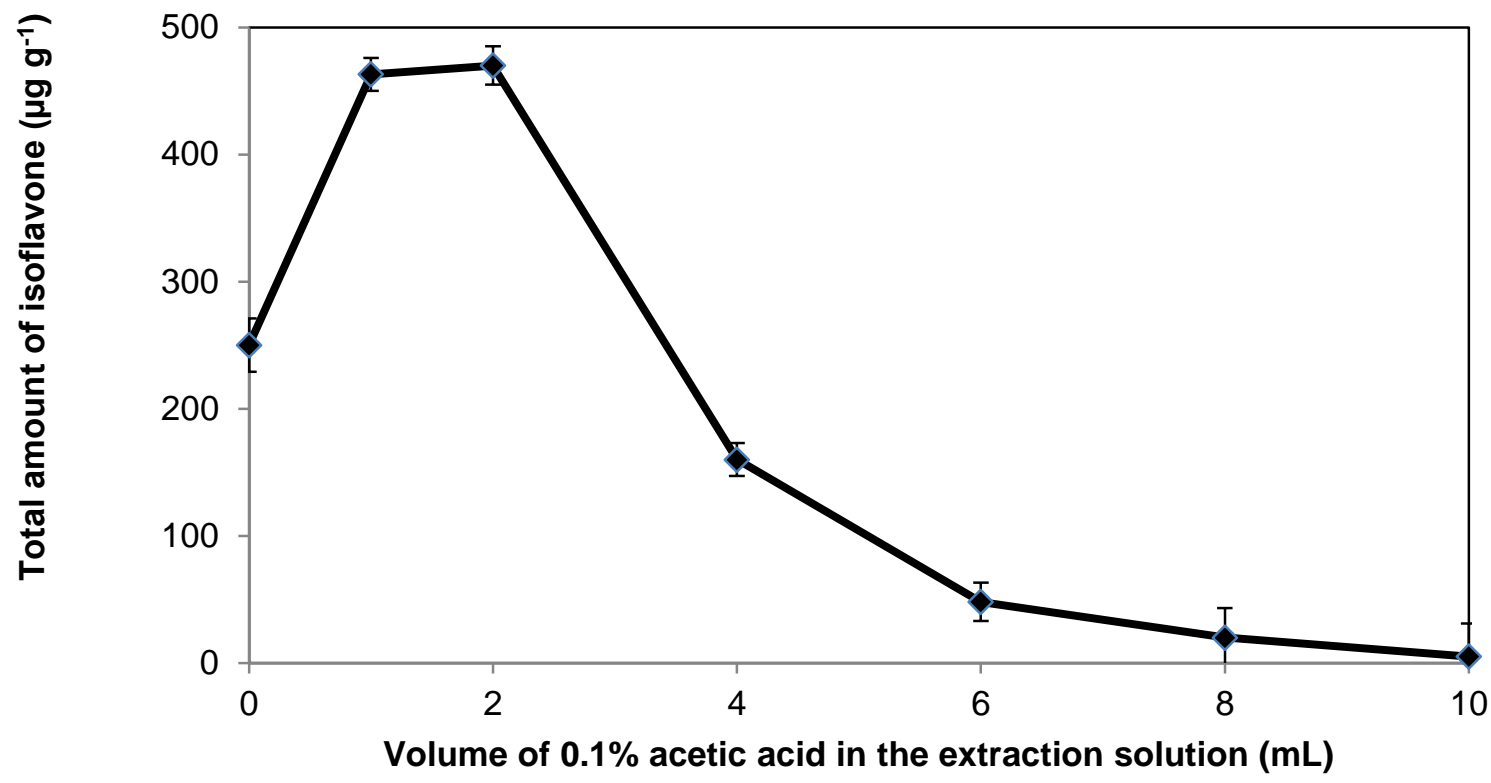

Figure 4. Volume of $0.1 \%$ acetic acid in the extraction solution.

\section{Determination of Extraction Conditions}

A series of almond samples were prepared to determine the centrifugal speed. Extraction solution was added to the samples. The centrifugation time was kept constant for 4 minutes and the prepared samples were centrifuged at 2000, 4000, 6000, 8000, 10000 and $12000 \mathrm{rpm}$ (Rotation per minute). The content of extracted solutions were analyzed by HPLC device and the total amount of isoflavone was calculated. As can be seen in Figure 5, the best results for the total amount of isoflavone are obtained at 8000 - $12000 \mathrm{rpm}$ to centrifugation speed. 


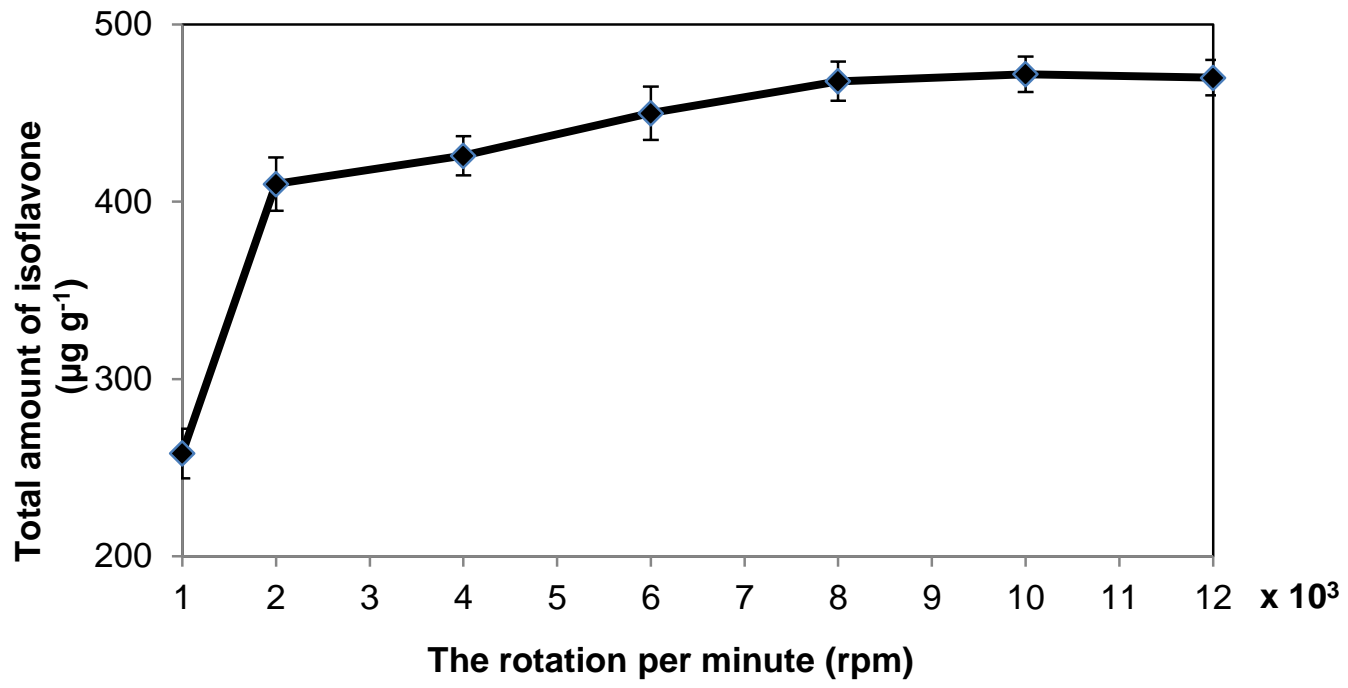

Figure 5. The rotation per minute in the extraction process.

For subsequent experiments, the centrifugation speed was chosen at $10000 \mathrm{rpm}$. A series of almond samples were prepared to determine the extraction time.

While the centrifugation speed was kept constant at $10000 \mathrm{rpm}$, the prepared samples were centrifuged respectively at 1,2, 3, 4 and 5 minutes. The total amount of isoflavone was calculated in the same way. As seen in Figure 6, centrifugation time was selected to 4 minutes.

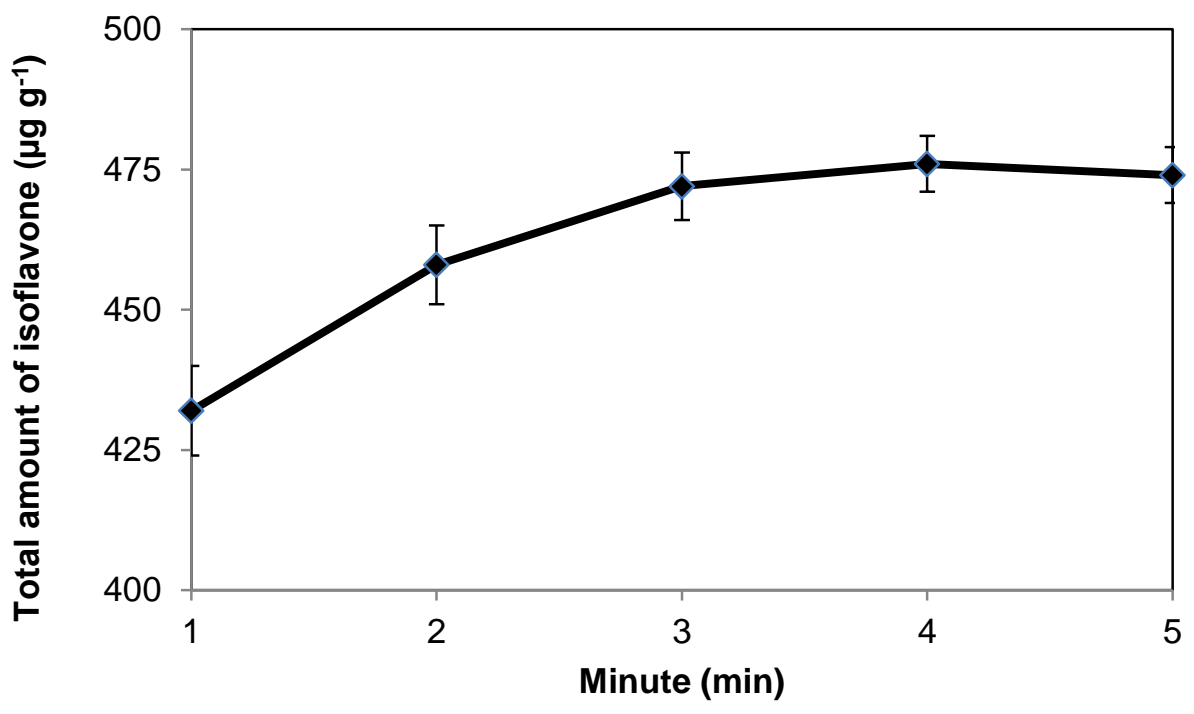

Figure 6. Centrifuge time.

\section{Calculation of Analytical Parameters}

In order to determine the detection limit is firstly calculated. For this reason, the blank samples $(n=21)$ were prepared and the developed extraction method was applied to these samples. Amounts of daidzin, daidzein and genistein were determined on the C18 column in the HPLC device. The dedection limits for daidzin, daidzein and genistein respectively were calculated as $0.28,0.28$ and $0.29 \mathrm{mg} \mathrm{L}^{-1}$ and the quantification limits were calculated as $0.92,0.94$ and $0.97 \mathrm{mg} \mathrm{L}^{-1}$. In order to calculate the recovery of the method, after samples were prepared at the known concentrations of daidzin, daidzein and 
genistein compounds, the developed method was applied. Isoflavones were determined by HPLC. The concentrations of daidzin, daidzein and genistein were calculated according to the calibration line. It was found that recovery is in the range of $95-103 \%$. The relative standard deviation of the method is $\leq 3 \%$ for 21 real samples. The working range was set in 1-100 $\mathrm{mg} \mathrm{L}^{-1}$. Standard solutions were prepared at the concentrations of $1,5,10,20,50$ and $100 \mathrm{mg} \mathrm{L}^{-1}$ for the calibration line.

\section{Method Application to Samples}

The developed method was applied to nuts, dried fruit and vegetable samples purchased from Sivas center. For each of samples, three parameters have been studied. As shown in Table 3, while the maximum value of the daidzin amount in the samples was found as $386.1 \mu \mathrm{g} \mathrm{g}^{-1}$ in almond and the minimum value of its was found as $10.4 \mu \mathrm{g} \mathrm{g}^{-1}$ in the dry yellow grape. In addition that, the amount of daidzein was calculated as $9.6 \mu \mathrm{g} \mathrm{g}^{-1}$ in dry pepper, $14.6 \mu \mathrm{g} \mathrm{g}^{-1}$ in dry bean, $24.6 \mu \mathrm{g} \mathrm{g}^{-1}$ in almond, and the amount of genistein was calculated as $8.4 \mu \mathrm{g} \mathrm{g}^{-1}$ in dry bean and $58.4 \mu \mathrm{g} \mathrm{g}^{-1}$ in almond. The results are given considering the dry weight of the samples.

Table 3. Amounts of daidzin, daidzein and genistin $\left(\mu \mathrm{g} \mathrm{g}^{-1}\right)$ in the real samples taken from Sivas center $(\mathrm{n}=3)$.

\begin{tabular}{lcccc}
\hline Sample & Daidzin & Daidzein & Genistein & Total Isoflavone \\
\hline Almond & $386.1 \pm 3.5^{\mathrm{a}}$ & $24.6 \pm 1.4$ & $58.4 \pm 3.9$ & 469.1 \\
Hazelnut & $12.2 \pm 1.2$ & $-\mathrm{b}$ & - & 12.2 \\
Peanut & $25.4 \pm 3.0$ & - & - & 25.4 \\
Dry eggplant & $172.6 \pm 6.2$ & - & - & 172.6 \\
Dry pepper & - & $9.6 \pm 0.5$ & - & 9.6 \\
Dry squash & $56.2 \pm 4.2$ & - & - & 56.2 \\
Haricot bean & $168.5 \pm 15.0$ & $14.6 \pm 1.3$ & $8.4 \pm 1.2$ & 191.5 \\
Dry apricots & $18.9 \pm 1.0$ & - & - & 18.9 \\
Dry yellow grape & $10.4 \pm 0.4$ & - & - & 10.4 \\
Dry black grapes & $66.5 \pm 7.2$ & - & - & 66.5 \\
\hline
\end{tabular}

${ }^{\mathrm{a}}$ Average \pm standard deviation; ${ }^{\mathrm{b}}$ Below detection limit.

\section{DISCUSSION AND CONCLUSION}

Search of the rich foods as phytoestrogen has increasingly become important due to the beneficial and deleterious effects of phytoestrogens on the living things. Although there have been many studies (Liggins et al., 2000; Krenn et al, 2002; Fukudaet al., 2011; Thomaset al., 2001; Zafra-Gómezet al., 2010) on the determination of isoflavones in various plant and food samples such as especially soybean and soy products, there is very little isoflavone determination study related to the contents of nuts, dried fruits and vegetables.

As seen in Table 4, Toro-Funes et al. reported that the highest amount of daidzin was at 1138.16 $\mu \mathrm{g} \mathrm{g}^{-1}$ in soybean milk (Toro-Funeset al., 2012). The amounts of daidzin, daidzein and genistein were quantified by Delgado-Zamarreno et al. in lentils and white beans, especially genistein was determined at $0.0310 \mu \mathrm{g} \mathrm{g}^{-1}$ in chick pea Delgado-Zamarreno et al.2012). The soy and cherry samples were examined by Abranko et al. and three isoflavone derivatives were also evaluated in soy and the genistein was found the value in the range of 4.0-6.0 $\mu \mathrm{g} \mathrm{g}^{-1}$ in cherry from these derivatives (Abranko et al., 2015). Three isoflavones in soybean samples were identified by Ribeiro et al. andthe values were found for daidzin, daidzein and genistein in range respectively, as 61.8-161.7, 4.9-15.8 and 4.1-21.7 $\mu \mathrm{g} \mathrm{g}^{-1}$ (Ribeiro et al.,2007). Daidzin, daidzein and genistein quantities on legumes were examined by Vila Donat et al. andobtained a maximum value at $517.4 \mu \mathrm{g} \mathrm{kg}^{-1}$ for daidzin (Vila Donat et al., 2015). 
In this study, nuts, dried fruits and vegetables, which get from local markets in Sivas, was extracted under optimum conditions. After then, it was determined the amounts of daidzin, daidzein and genistein compounds by HPLC. New informations with respect to the amount of isoflavones of nuts, dried fruits and vegetables that containing an important place in our nutrition, have been obtain in this study. In this respect, the amounts of daidzin, daidzein and genistein of isoflavone derivatives have been determined.

Table 4. Some recent studies on amounts of daidzin, daidzein and genistein in various food samples.

\begin{tabular}{|c|c|c|c|c|c|}
\hline Instrument & Sample & $\begin{array}{l}\text { Daidzin } \\
\left(\mu g^{-1}\right)\end{array}$ & $\begin{array}{l}\text { Daidzein } \\
\left(\mu g^{-1}\right)\end{array}$ & $\begin{array}{c}\text { Genistein } \\
\left(\mu g^{-1}\right)\end{array}$ & Referans \\
\hline \multirow[t]{3}{*}{$\begin{array}{l}\text { Ultra-performance liquid chromatography - } \\
\text { Mass spectrometry }\end{array}$} & Chickpea & $-{ }^{a}$ & - & 0.0310 & $\begin{array}{c}\text { (Delgado- } \\
\text { Zamarreno et al., } \\
\text { 2012) }\end{array}$ \\
\hline & Lentil & 0.0177 & 0.0250 & 0.1030 & \\
\hline & $\begin{array}{l}\text { White } \\
\text { Bean }\end{array}$ & 0.0052 & 0.0263 & 0.0135 & \\
\hline $\begin{array}{l}\text { UV detector - Ultra high pressure liquid } \\
\text { chromatography }\end{array}$ & Soy milk & 1138.16 & 43.32 & 77.38 & $\begin{array}{c}\text { (Toro-Funes et al., } \\
\text { 2012) }\end{array}$ \\
\hline $\begin{array}{l}\text { High performance liquid chromatography - } \\
\text { electrospray ionization - Mass spectrometry }\end{array}$ & Cherry & $-\mathrm{b}$ & - & $4.0-6.0$ & $\begin{array}{c}\text { (Abrankó et al., } \\
\text { 2015) }\end{array}$ \\
\hline High performance liquid chromatography & Soy & $61.8-161.7$ & $4.9-15.8$ & $4.1-21.7$ & $\begin{array}{l}\text { (Ribeiro et al., } \\
\text { 2007) }\end{array}$ \\
\hline \multirow[t]{5}{*}{$\begin{array}{l}\text { Ultra high performance liquid } \\
\text { chromatography - Mass spectrometry }\end{array}$} & $\begin{array}{l}\text { Spanish } \\
\text { lentils } \\
\left(\mu \mathrm{g} \mathrm{kg}^{-1}\right)\end{array}$ & 1.3 & 1.3 & 2.9 & $\begin{array}{l}\text { (Vila Donat et al., } \\
\text { 2015) }\end{array}$ \\
\hline & $\begin{array}{l}\text { Soy } \\
\left(\mu \mathrm{g} \mathrm{kg}^{-1}\right)\end{array}$ & 517.4 & 35.8 & 30.9 & \\
\hline & $\begin{array}{l}\text { Chickpea } \\
\left(\mu \mathrm{g} \mathrm{kg}^{-1}\right)\end{array}$ & 319.6 & 34.3 & 26.4 & \\
\hline & $\begin{array}{l}\text { Borlotto } \\
\text { Beans } \\
\left(\mu \mathrm{g} \mathrm{kg}^{-1}\right)\end{array}$ & 202.2 & 12.6 & 9.6 & \\
\hline & $\begin{array}{l}\text { Pea } \\
\left(\mu \mathrm{g} \mathrm{kg}^{-1}\right)\end{array}$ & 99 & 28 & 31.3 & \\
\hline
\end{tabular}

${ }^{\mathrm{a}}$ Average \pm standard deviation, ${ }^{\mathrm{b}}$ Below detection limit.

DL: Detection Limit; PL: Preconcentration Limit; PF: Preconcentration Factor.

\section{ACKNOWLEDGEMENT}

This study was supported with GMYO-002 number project of Sivas Cumhuriyet University Scientific Research Projects Department.

\section{REFERENCES}

Abrankó L, Nagy A, Szilvássy B, Stefanovits-Bányai E, Hegedüs A, 2015. Genistein isoflavone glycoconjugates in sour cherry (Prunus cerasus L.) cultivars. Food Chemistry,166: 215-222.

Barros F, Dykes L, Awika JM, Rooney LW, 2013. Accelerated solvent extraction of phenolic compounds from sorghum brans. Journal of Cereal Science, 58: 305-312.

Bingham SA, Atkinson C, Liggins J, Bluck L,Coward A, 1998. Phytooestrogens: whereare we now? British Journal of Nutrition, 79: 393-406.

Brglez Mojzer E, Knez Hrncic M, Skerget M, Knez Z, Bren U, 2016. Polyphenols: Extraction methods, antioxidative action, bioavailability and anticarcinogenic effects. Molecules, 2: 901. 
Cos P, Bruyne TD, Apers S, Berghe DV, Pieters L, Vlietinck AJ, 2003. Phytoestrogens: Recent Developments. Planta Medica, 69: 589-599.

Delgado-Zamarreno MM, Perez-Martin L, Bustamante-Rangel M, Carabias-Martinez R, 2012. A modified QuErChers method as a sample treatment before the determination of isoflavones in foods by ultra-performance liquid chromatography-triple quadrupole mass spectrometry. Talanta, 100: 320-32.

Delmonte P, Perry J, Rader JI, 2006. Determination of isoflavones in dietary supplements containing soy, Red Clover and Kudzu: Extraction followed by basic or acid hydrolysis. Journal of Chromatography A, 1107: 59-69.

Durmaz G, Gökmen V, 2010. Impacts of roasting oily seeds and nuts on their extracted oils. Lipid Technology, 22(8): 179-182.

Grace PB, Taylor JI, Botting NP, Fryatt T, Oldfield MF, Bingham SA, 2003. Quantification of isoflavones and lignans in urine using gas chromatography/mass spectrometry. Analytical Biochemistry, 315: 114-121.

Franke AA, Custer LJ, Wilkens LR, Marchand LL, Nomura AMY, Goodman MT, Kolonel LN, 2002. Liquid chromatographic- photodiode array mass spectrometric analysis of dietary phytoestrogens from human urine and blood. Journal of Chromatography B, 777: 45-59.

Fukuda I, Tsutsui M, Yoshida T, Toda T, Takanori T, Ashida H, 2011. Oral Toxicological Studies of Black Soybean (Glycine Max) Hull Extract: Acute Studies in Rats and Mice, And Chronic Studies in Mice. Food and Chemical Toxicology, 49(12): 3272-3278.

King JC, Rechkemmer G, Constance JG, 2008. Second International Nuts and Health Symposium, 2007: Introduction. The Journal of Nutrition, 138( 9): 17345-17355.

Klejdus B, Vacek J, Adam V, Zehnalek J, Kizek R, Trnkova L, Kuban V, 2004. Determination of isoflavones in soybean food and human urine using liquid chromatography with electrochemical detection. Journal of Chromatography B, 806: 101-111.

Krenn L, Unterrieder I, Ruprechter R, 2002. Quantification of isoflavones in red clover by highperformance liquid chromatography. Journal of Chromatography B, 777: 123-128.

Küçükboyacı N, Kadığlu O, Adıgüzel N, Tamer U, Güvenç A, Bani B, 2013. Determination of Isoflavone Content by HPLC-UV Method and in vitro Antioxdant Activity of Red Clover (Trifolium Pratense L.). Turkish Journal of Pharmceutical Sciences, 10(3): 463-472.

Liggins J, Bluck LJ, Runswick S, Atkinson C, Coward WA, Bingham SA, 2000. Daidzein and genistein contents of vegetables. British Journal of Nutrition, 84(5): 717-725.

Maubach J, Bracke ME, Heyerick A, Depypere HT, Serreyn RF, Mareel MM, Keukeleire DD, 2003. Analytical Technologies in the Biomedical and Life Sciences. Quantitation of soy-derived phytoestrogens in human breast tissue and biological fluids by high-performance liquid chromatography. Journal of Chromatography B, 784: 137-144.

Modaseri M, Messripour M, Khorami H, 2011. Effect of Soybean on Male Reproductive Physiology in Mice. International Conference on Life Science and Technology, 3: 15-18.

Naim M, Gestetner B, Zilkah S, Birk Y, and Bondi A, 1974. Soybean Isoflavones. Characterization, Determination, and Antifungal Activity. Journal of Agricultural and Food Chemistry, 22: 806810.

Luque-Garcia JL, Luque de Castro MD, 2004. Ultrasound-assisted Soxhlet extraction: an expeditive approach for solid sample treatment. Aplication to the extraction of total fat from oleaginous seeds. Journal of Chromatography A, 1034: 237-242. 
Özhatay N, Kültür Ş, Arslan S, 2009. Check-list of additional taxa to the supplement Flora of Turkey IV. Turkish Journal of Botany, 33: 191-226.

Prior RL, Cao G,1999. Assessing antioxidant capacity in plant foods. Free Radical Biology \& Medicine, 27: S11-S.

Prior RL, Wu X, Schaich K, 2005. Standardized methods for the determination of antioxidant capacity and phenolics in foods and dietary supplements. Journal of Agricultural and Food Chemistry, 53: 4290-302.

Ribeiro MLL, Mandarino JMG, Carrao-Panizzi MC, Oliveira MCN, Campo CBH, Nepomuceno AL, Ida EI, 2007. Isoflavone content and b-glucosidase activity in soybean cultivars of different maturity groups. Journal of Food Composition and Analysis, 20: 19-24.

Rostagno MA, Villares A, Guillamon E, García-Lafuente A, Martínez, JA, 2009. Sample preparation for the analysis of isoflavones from soybeans and soy foods. Journal of Chromatography A, 1216: $2-29$.

Stratil P, Klejdus B, Kuban V,2006. Determination of totalcontent of phenolic compounds and their antioxidantactivity in vegetables - Evaluation of spectrophotometricmethods. Journal of Agricultural and Food Chemistry, 54:607-616.

Thomas BF, Zeisel SH, Busby MG, Hill JM, Mitchell RA, Scheffler NM, Brown SS, Bloeden LT, Dix $\mathrm{KJ}$, Jeffcoat AR, 2001. Quantitative analysis of the principle soy isoflavones genistein, daidzein and glycitein, and their primary conjugated metabolites in human plasma and urine using reversed-phase high-performance liquid chromatography with ultraviolet detection. Journal of Chromatography B, 760: 191-205.

Toro-Funes N, Odriozola-Serrano I, Bosch-Fuste J, Latorre-Moratalla ML, Veciana-Nogues MT, Izquierdo-Pulido M, Vidal-Carou MC, 2012. Fast simultaneous determination of free and conjugated isoflavones in soy milk by UHPLC-UV. Food Chemistry, 135: 2832-2838.

Tsao R, 2010. Chemistry and biochemistry of dietary polyphenols. Nutrients, 2: 1231-1246.

Vila-Donat P, Caprioli G, Maggi F, Ricciutelli M, Torregiani E, Vittori S, Sagratini G, 2015. Effective clean-up and ultra high-performance liquid chromatography-tandem mass spectrometry for isoflavone determination in legumes. Food Chemistry, 174: 487-494.

Xiao HB, Krucker M, Albert K, Liang XM, 2004. Determination and identification of isoflavonoids in Radix astragali by matrix solid-phase dispersion extraction and high-performance liquid chromatography with photodiode array and mass spectrometric detectionJournal of Chromatography A, 1032: 117-124.

Zafra-Gómez A, Garballo A, García-Ayuso LE, Morales Juan C, 2010. Improved sample treatment and chromatographic method for the determination of isoflavones in supplemented foods. Food Chemistry, 123: 872-877. 